\title{
Concepções docentes sobre o construtivismo e sua implantação na rede estadual de ensino fundamental
}

\author{
Patrícia Rossi Carraro \\ Antônio dos Santos Andrade
}

\section{Resumo}

No presente relato de pesquisa, são apresentadas as concepções dos professores sobre o construtivismo, investigadas através de entrevista com quarenta professores do ensino fundamental de duas escolas de uma cidade do interior de São Paulo. As entrevistas foram gravadas e transcritas literalmente, e os resultados foram submetidos à Análise de Conteúdo. As entrevistas indicaram que a maioria dos professores tem uma noção imprecisa sobre o construtivismo. Os professores consideraram que, devido à falta de estudo, orientação e apoio da escola, não têm preparo para trabalharem com o construtivismo. Dessa forma, supõe-se que os pressupostos construtivistas não foram transmitidos de maneira adequada aos docentes. Constatou-se que, para os professores, o construtivismo foi mais uma reforma educacional imposta a eles. De maneira geral, os professores não são desfavoráveis à implantação do construtivismo no cotidiano escolar, porém não concordam com a forma como se deu essa implantação.

Palavras-chave: Construtivismo, atividade pedagógica, ensino fundamental.

\section{Teachers' conceptions of constructivism and its implementation in the state elementary education.}

\begin{abstract}
In this study we investigate teachers' conceptions of constructivism. We interviewed forty teachers from two elementary schools in the countryside of the state of São Paulo. The interviews were tape-recorded and transcribed literally. Content Analysis was used to analyze the data. The results indicated that most teachers have an imprecise notion of Constructivism. The teachers considered that, due to the lack of study, guidance and support from the school, they are unprepared to adopt constructivist pedagogy. Thus, it is possible to suggest that the constructivist presuppositions have been transmitted to teachers through an inadequate strategy. For these professionals, Constructivism seems to represent one more educational reform which was imposed on them. In general, the teachers revealed to be favorable to the implementation of Constructivism in their classrooms. However they disagree with the way it has been implemented.
\end{abstract}

Keywords: Constructivism, educational activity, fundamental education.

\section{Concepciones docentes sobre el constructivismo y su implantación en la red estatal de enseñanza primaria}

\section{Resumen}

En el presente relato de investigación son presentadas las concepciones de los profesores sobre el constructivismo, investigadas a través de entrevista con cuarenta profesores de la enseñanza primaria de dos escuelas de una ciudad del interior de São Paulo. Las entrevistas fueron grabadas y transcritas literalmente y los resultados fueron sometidos a Análisis de Contenido. Las entrevistas indicaron que la mayoría de los profesores tiene una noción imprecisa sobre el constructivismo. Los profesores consideraron que, debido a la falta de estudio, orientación y apoyo de la escuela, ellos no tienen preparo para trabajar con el constructivismo. De esta forma, se supone que los postulados constructivistas no fueron transmitidos de manera adecuada para los profesores. Se constató que, para los profesores, el constructivismo fue una reforma educativa más a ellos impuesta. En general, los profesores no son desfavorables a la implementación del constructivismo en el cotidiano escolar, sin embargo no están de acuerdo con la forma de cómo se realizó esa implantación.

Palabras-clave: Construvismo, actividad pedagógica, educación primaria. 


\section{Introdução}

A concepção construtivista trouxe, por meio de grandes repercussões, modificações às ideias, às práticas pedagógicas dos educadores e ao cotidiano escolar, tornando-se ao longo dos tempos o centro das atenções no âmbito educacional.

Para Macedo (1993), o construtivismo, com ênfase em sua função educacional, pode ser analisado através das oposições entre a visão construtivista (ação do sujeito; tematização; tornar-se; teoria da ação e ações espontâneas) e não-construtuvista (transmissão; paradigma; ser; teoria da representação da realidade eaçãoinduzida)do conhecimento. Isso quer dizer que, a uma "visão-construtivista" do conhecimento, interessam as ações do sujeito que conhece; ressalta-se o trabalho constante da reconstituição do que já se sabe, exigindo para isso a descentração e a coordenação dos diferentes pontos de vista. O conhecimento é entendido ainda como um "tornar-se" antes de ser; sem falar que o conhecimento a respeito de algo só pode ocorrer enquanto uma teoria da ação, na perspectiva lógico-matemática, e não como uma teoria da realidade, e, por último, essa visão dá ênfase à ação espontânea ou apenas desencadeada, jamais induzida. A visão construtivista está fundamentada na proposta de Piaget (1976), na qual a constituição do(s) objeto(s) e de suas relações é feita em vários níveis, conduzindo, para o núcleo de sua teoria, a equilibração, que explica as possibilidades cognitivas do indivíduo ao interagir com pessoas e coisas.

A partir da década de 70 , a perspectiva teórica construtivista começa a ser utilizada no Brasil em propostas, projetos e reformas educacionais. Recentemente, os Parâmetros Curriculares Nacionais (PCN) receberam inúmeras críticas ao adotarem como referência teórica o construtivismo (ANPEd, 1996; Azanha, 2001; Duarte, 2001; Moreira, 1996).

Carvalho(2001)relata que o discurso do construtivismo pedagógico, ao chegar no contexto educacional, ignorou totalmente o aluno, o professor e a própria escola. Nesse discurso, existem certos problemas oriundos da apropriação, da transposição direta e da aplicação acrítica de conceitos, definições e perspectivas de resultados da psicologia do desenvolvimento e da epistemologia genética de Jean Piaget para a área educacional.

Para Macedo (1994), a transformação da obra de Piaget é inevitável quando visamos à aplicação pedagógica; porém, é preciso estar atento para que os pressupostos de sua teoria sejam preservados, pois, de outra forma, o trabalho pedagógico não poderá mais se identificar com o construtivismo de Piaget. Nesse sentido, o construtivismo colocado em prática nas escolas só pode estar baseado em Piaget se os pressupostos de sua teoria psicológica e epistemológica forem considerados adequadamente.

Duarte (2001) ressalta que, nas últimas décadas, foi muito grande a divulgação da epistemologia e psicologia genética de Jean Piaget como referencial para a educação. Divulgação essa que foi feita através do movimento construtivista e que, no Brasil, tornou-se um modismo a partir dos anos 80 , defendendo princípios pedagógicos próximos aos do movimento escolanovista.

Para alguns autores como Hernández (1998), o construtivismo, apesar de não ser utilizado da maneira adequada, popularizou-se nas instituições de ensino. $\mathrm{Na}$ opinião deste autor, o construtivismo não é uma metodologia, muito menos uma técnica educacional, ou uma teoria determinada. Este está sendo visto como uma imposição gratuita ou, simplesmente, uma imposição metodológica muito prejudicial.

O autor acima, evidentemente, trata de uma posição radical em relação às possibilidades de aplicação dos pressupostos educacionais derivados do construtivismo.

As pesquisas que serão apresentadas a seguir enfatizam o fato de os pressupostos construtivistas não estarem sendo transmitidos de maneira adequada aos professores. Todavia, é preciso alertar que esse fato em nada desmerece ou coloca em descrédito tais pressupostos; trata-se, outrossim, de um mau uso do construtivismo que só pode depor contra sua apropriação inadequada.

Torres (2004) realizou uma investigação sobre a possível resistência ao construtivismo piagetiano por parte das professoras da rede pública de ensino de Ribeirão Preto/ S.P. e suas possíveis causas. A pesquisa foi realizada com oito professoras de $1^{\mathrm{a}}$ à $4^{\mathrm{a}}$ série do ensino fundamental. Como método, foram utilizadas a entrevista semiestruturada e a técnica das palavras-chave. A análise, de natureza qualitativa, focalizou três blocos temáticos: a questão da mudança em educação; concepção de construtivismo; e resistência versus aceitação da teoria. Os resultados indicam que há resistência (às vezes não propriamente manifesta) ao construtivismo. Este é concebido pelas professoras de modo deformado, fragmentado, pontual. É também confundido com método de alfabetização, com não usar a cartilha, com técnica de recorte de letras para a construção de palavras, com "partir do aluno" ou do que ele "traz de casa" e até com indisciplina e não correção de erros do aluno. O construtivismo chegou aos professores de forma simplificada, como um método de ensino que determina quais atitudes o professor deve abandonar e quais deve adotar. Isso parece ter contribuído para que a reação das professoras fosse negativa diante da teoria. Torres (2004) enfatiza que, antes de propor aos professores um trabalho baseado no construtivismo, é necessário pensar em sua formação, que seria o prérequisito para a compreensão desta teoria.

O trabalho de Silva (2005) investigou o conhecimento de professores do ensino fundamental da escola pública a respeito do construtivismo. A pesquisa foi realizada com 20 professores de diversas disciplinas de $5^{a}$ à $8^{a}$ séries do ensino fundamental e 07 professores formadores, sendo 06 de diretorias de ensino da região onde a pesquisa foi realizada e 01 coordenador pedagógico. Os depoimentos foram organizados a partir de três categorias de análises (slogan, distorção e concepção construtivista), de acordo com os seguintes temas: definição de construtivismo, aprendizagem, desenvolvimento, autonomia, papel do 
professor e conteúdos escolares. Os resultados apontam que os conhecimentos que os professores e formadores do ensino fundamental têm a respeito do construtivismo são frequentemente distorcidos e baseados em slogans. Os professores e formadores não mostraram conhecimento mais aprofundado do construtivismo e nem da teoria piagetiana. Os professores distorcem mais e os formadores usam mais slogans. Os conhecimentos que apresentaram evidenciam uma correspondência com as orientações tanto de textos de autores construtivistas, como dos materiais de orientações didáticas elaboradas pelos órgãos governamentais. Os caminhos que esses conhecimentos fizeram para chegar até os professores e, consequentemente, até a sala de aula, passam pelas capacitações, leituras (de revistas sobre educação e livros), projetos e orientações pedagógicas recebidas nas diretorias de ensino (com os formadores) e na própria escola, durante os Horários de Trabalho Pedagógico Coletivo (HTPC). Além disso, sem conhecimento suficiente, os professores transpõem para a prática de sala de aula algumas orientações didáticas, mesmo não havendo preparo adequado para isso. O construtivismo, na própria visão dos professores, exige um conhecimento que eles não têm, e o que aprenderam na formação não foi suficiente para lhes dar o respaldo necessário para a prática.

Segundo Queiroz e Barbosa-Lima (2007), está ocorrendo uma adesão indiscriminada de muitas pessoas ao constructo construtivista sem maiores esclarecimentos sobre a base teórica usada, entre as muitas que podem ser consideradas sob a denominação construtivista. Essas autoras defendem que esse enfoque teórico se tornou orientador para muitas pesquisas conseguindo reunir valores, teorias e modelos (de ensino-aprendizagem) respeitados por uma comunidade de especialistas em Educação, os quais o adotaram, como base teórica para a resolução de uma série de problemas/dilemas da prática, no campo da formação de educadores em Ciências.

Apesar do construtivismo ter sido alvo de críticas, sendo muitas vezes mal interpretado, encontramos pesquisas realizadas no Brasil que procuram ressaltar, também, a importância, os aspectos favoráveis e as dificuldades de se trabalhar com essa teoria. Em dois estudos, Ribeiro (1997) analisou a noção de professores sobre o construtivismo e a maneira como articulam essa teoria com a prática pedagógica. No primeiro, 53 professores responderam a um questionário e, no segundo, um grupo de cinco professores em formação há dois anos em uma escola construtivista responderam ao mesmo questionário e também a uma entrevista. Os resultados obtidos indicam, em primeiro lugar, que a noção dos professores sobre o construtivismo é influenciada tanto por certas ideias da Escola Nova, como pelos textos publicados na década de 80 por Emilia Ferreiro e Ana Teberosky, considerados, pelos próprios professores, como importantes para subsidiar a prática pedagógica. Em segundo lugar, os resultados mostram que, quando articulam a teoria construtivista com a prática, os professores apresentam ideias ora mais próximas de princípios empiristas, ora mais próximas de princípios espontaneístas, sugerindo que essa articulação poderia ser melhor desenvolvida por meio da formação continuada de professores.

Massabni (2005) estudou a concepção construtivista de dez professores de Ciências do ensino fundamental que afirmaram concordar com o "modo de pensar" do construtivismo e com sua adaptação à prática educativa. Para a análise dos dados, foram utilizados como parâmetros a teoria piagetiana e os princípios construtivistas, além de estudos sobre professores que, na perspectiva da racionalidade prática, valorizam seus saberes. Constatou-se que há grande aceitação do construtivismo como referencial teórico, mas que existe insegurança e críticas quanto a colocar a teoria em prática. Uma parte das dificuldades relatadas diz respeito ao construtivismo como fundamento da prática, como, por exemplo, relacionar determinados conteúdos ao cotidiano. Outra dificuldade está relacionada à escola e envolve o desinteresse dos alunos em sala, a falta de apoio e de materiais e a intensificação do trabalho, agravada no construtivismo e considerada desgastante pelos docentes. Por outro lado, demonstrou-se que o construtivismo tem a vantagem de impor maior respeito ao ritmo e às diferenças intelectuais entre os alunos.

Os trabalhos que serão apresentados a seguir indicaram que os professores, ao receberem formação dos pressupostos construtivistas, tiveram uma maior compreensão sobre o assunto, apesar das dúvidas e receios quanto à inserção do construtivismo no contexto educacional.

Welsch-Kinnucan e Jenlink (1998) realizaram um estudo de caso com três grupos de educadores que participaram de uma experiência de capacitação profissional em três regiões de Michigan. Esse trabalho de capacitação, cuja fundamentação teórica foi o construtivismo, baseou-se em leituras, discussões e atividades práticas com estudantes sobre o processo ensino-aprendizagem. Os instrumentos metodológicos utilizados foram: videoteipe para as atividades de grupo; entrevistas de grupos focais; notas de campo; e registros dos educadores. Os resultados indicaram que a maioria dos professores não acreditava na viabilidade da pedagogia construtivista e que alguns deles não se sentiam preparados para trabalharem com a nova perspectiva teórica. Apesar dos autores terem concluído que os professores não acreditavam na viabilidade da implantação do construtivismo, estes mesmos autores, neste mesmo artigo, defendem a necessidade de se criar estratégias que levem os professores a superarem esta crença.

Tatto (1998) analisou dados de uma pesquisa realizada com professores e universitários que pretendiam se tornar docentes e que haviam participado de programas de formação com fundamentação teórica considerada construtivista. O propósito do trabalho foi o de investigar as convicções dos participantes sobre a educação, o papel do professor e a prática pedagógica. Como instrumento metodológico, foram examinadas informações do estudo "Teacher Education and Learning to Teach (TELT)", realizado pelo National Center for Research on Teacher Education (NCRTE), em que questionários foram aplicados e entrevistas foram realizadas com os participantes da pesquisa no período de 1985 a 
1990. Em relação às convicções a respeito da educação, observou-se que os professores acreditavam que seria um modo de desenvolver nos alunos pensamento crítico e um maior entendimento sobre o mundo que os rodeia. Com relação ao papel do professor, todos colocaram que a principal função do professor era encorajar os estudantes a construírem seu conhecimento e questionarem o mundo. Em contrapartida, para os universitários que pretendiam se tornar docentes, a principal função do professor seria a de ensinar a matéria. No que se refere à prática pedagógica, os resultados demonstraram que os professores preferiam utilizar formas diferentes de ensinar. Concluiu-se que a teoria construtivista tem implicações significativas em programas de formação de professor.

Outro exemplo de um trabalho realizado com a concepção construtivista é o de Brewer e Daane (2002), que fizeram um estudo com oito professores de matemática de uma escola de primeiro grau dos Estados Unidos que se consideravam construtivistas. Esses professores se formaram em uma universidade que utilizava a filosofia construtivista no programa de educação de professores e, portanto, consideravam que o construtivismo era a teoria que orientava suas ações educacionais. O objetivo dessa pesquisa foi o de investigar as convicções dos professores sobre a teoria construtivista e sua aplicação na sala de aula. Como instrumentos metodológicos, foram realizadas entrevistas individuais e, posteriormente, observações em sala de aula, as quais foram gravadas em videoteipe. A partir das entrevistas foram encontrados quatro temas. Dentre esses temas, destacam-se, para os professores entrevistados, que os alunos constroem seu próprio conhecimento a partir do conhecimento que eles possuem; e que o trabalho com outros professores possibilitou entender melhor o ensino construtivista. Os autores desse estudo concluíram que os professores conseguiram unir a filosofia construtivista e o ensino de matemática no primeiro grau.

Tatto (1999) realizou uma pesquisa com professores rurais do México após a implantação de um programa inovador baseado na teoria do construtivismo, denominado de PARE (Programa para Abatir el Rezago Educativo). O objetivo do estudo foi investigar os desafios e as tensões envolvidas na implantação de uma reforma educacional que segue princípios construtivistas. Como instrumentos metodológicos, foram analisados relatórios de pesquisa e documentos do programa, realizadas observações em sala de aula e na escola e, por último, entrevistas com os dirigentes do programa e com os participantes (professores, diretores e supervisores). A autora considerou que alguns professores pareciam envolvidos com a teoria e pelo o que esta poderia significar na prática. Contudo, outros relataram que poderiam ter dificuldades de aplicação da teoria na sala de aula. Alguns professores relataram que, apesar do curso teórico oferecido pelo programa ter sido muito proveitoso, não seria fácil pôr em prática a teoria construtivista se não tivessem apoio e orientação. A conclusão foi a de que a escola precisa propiciar formação contínua para todos os docentes, tanto para os que estão atuando na escola como para os ingressantes na mesma, caso se deseje que todos se envolvam com a proposta construtivista.

Os estudos citados anteriormente servem como indicadores das pesquisas sobre a importância e o valor do uso do construtivismo como referencial teórico para a formação e a prática de professores. No Brasil, a implantação dos novos Parâmetros Curriculares Nacionais (PCN), que têm como base o construtivismo, levou à revalorização deste referencial. Considerando que a rede pública de ensino vem sendo submetida à "implantação" dos PCN, o presente estudo teve por objetivo caracterizar as concepções e convicções de professores de ensino fundamental de escolas da rede pública do Estado de São Paulo sobre a perspectiva construtivista.

A partir de nossos estudos sobre o construtivismo, considera-se que este não é uma teoria educacional da qual resultam instruções para a ação pedagógica. $\mathrm{Na}$ verdade, o construtivismo deve ser entendido como a posição epistemológica defendida por Piaget (2000) de que o conhecimento não é dado, mas sim construído pelas ações do sujeito quando este interage com os objetos, contrapondose ao empirismo e ao inativismo. Em nossa concepção, o construtivismo é uma perspectiva teórica relevante para a educação que procura conhecer o desenvolvimento da inteligência humana e a esta adequar, complementar e auxiliar os métodos de ensino.

\section{Metodologia}

\section{Participantes}

A pesquisa foi realizada com 40 professores do ensino fundamental de duas escolas da rede pública estadual de ensino de uma cidade do interior de São Paulo. Na primeira escola, denominada de Escola "A", foram entrevistados 20 professores do Ciclo II do Ensino Fundamental e, na segunda escola, denominada de Escola "B", foram entrevistados 20 professores, sendo 10 do Ciclo I (primeira à quarta série do ensino fundamental) e 10 do Ciclo II (quinta à oitava série do ensino fundamental) ${ }^{1}$.

\section{Procedimento de Coleta de Dados}

Como instrumento metodológico, foi utilizada a entrevista de profundidade em duas sessões. A primeira sessão teve por objetivo a contextualização da formação, história e prática profissional dos professores, bem como o estabelecimento de um vínculo mais favorável que facilitasse a fluidez e autenticidade da investigação sobre as concepções dos professores, a qual seria realizada na sessão seguinte. Nesta, foram investigadas as concepções e convicções em relação ao construtivismo, aos parâmetros curriculares nacionais (PCN) e às inovações pedagógicas.

Em lugar de um roteiro semiestruturado de pesquisa, foi utilizada uma estratégia menos estruturada, com o objetivo

1 Informações obtidas na Diretoria de Ensino na cidade onde a pesquisa foi realizada. 
de favorecer a manifestação dos professores. Os temas escolhidos para a primeira sessão foram: "As Experiências Anteriores"; "O Emprego Atual"; e a "A Prática em Sala de Aula". Os da segunda sessão foram: "O Construtivismo"; "Os Parâmetros Curriculares Nacionais" e as "Inovações Pedagógicas".

Em cada sessão, foram utilizados três cartões nos quais constava apenas um dos temas a ser investigado. Os três cartões, referentes a cada uma das duas sessões, eram colocados lado a lado sobre a mesa para que o entrevistado escolhesse o tema pelo qual gostaria de iniciar a entrevista. Os outros dois cartões eram guardados para serem utilizados em seguida. No primeiro momento, o entrevistado era indagado sobre o que lhe vinha à mente quando lia o tema escrito no cartão, quais eram os pensamentos, ideias e sentimentos que the ocorriam. Sugeria-se, então, que o entrevistado se dedicasse, pelo tempo que desejasse, a pensar, em silêncio, sobre o tema. No segundo momento, o entrevistado era solicitado a escrever, em uma folha de papel pautado contendo o tema escolhido na parte superior, as palavras ou expressões que vieram à sua mente, enquanto pensava, na primeira etapa, sobre o tema escolhido. No terceiro e último momento, o entrevistado, após ser informado de que o gravador seria ligado, era solicitado a explicar o sentido das palavras ou expressões da etapa anterior, uma a uma. Para iniciar, o entrevistado deveria responder à seguinte pergunta: "o que te fez lembrar esta palavra ou expressão quando você a escreveu?". A mesma pergunta era feita para cada uma das palavras ou expressões anotadas na etapa anterior. Esta "expansão" representa a fase da entrevista propriamente dita, pois é nela que se aprofunda a investigação, muito além das palavras e expressões registradas. Os assuntos foram explorados, com intervenção de esclarecimento apenas quando este era necessário, sempre tomando o cuidado de utilizar as próprias palavras e expressões já mencionadas pelo entrevistado. Esse procedimento foi realizado com todos os temas na primeira e na segunda sessão.

A estratégia descrita acima se constituiu numa adaptação, para fins de entrevista, de uma técnica padrão utilizada na evocação, enunciação e verificação de material para construção de escalas de atitudes, que se encontra bem descrita, por exemplo, no trabalho de Souza e Figueiredo (1993). A diferença principal do nosso procedimento é que, no caso da construção de escalas de atitudes, a terceira etapa, denominada de "verificação", naquele contexto, destina-se a colher apenas uma confirmação do sentido e significado que o entrevistado atribuiu à sua enunciação. No nosso caso, esta irá se constituir no material básico sobre o qual o pesquisador estará elaborando os itens que comporão a sua escala. Desta forma, a primeira etapa, funciona, para nós, como uma espécie de "associação livre", um recurso quase projetivo, que é depois registrado por escrito e então, expandido num discurso, no qual o entrevistado tem a oportunidade de explicitar e esclarecer o sentido que as "associações livres" iniciais têm para ele.

\section{Análise dos Dados}

Os dados das entrevistas, depois de transcritos na íntegra de suas audiogravações, foram submetidos à análise temática de conteúdo (Bardin, 1979; Minayo, 1998).

\section{Resultados}

A análise das entrevistas dos professores revelou cinco classes de categorias para os temas investigados: "O Construtivismo"; "O Construtivismo e as Diferentes Redes de Ensino"; "Os Estudos e Cursos sobre o Construtivismo"; "O Construtivismo e o Ensino e Aprendizagem" e "A Implantação do Construtivismo".

A maioria dos professores comentou que "Construtivismo" significa o aluno construir seu próprio conhecimento. Para outros, este seria um método de ensino. $\mathrm{Na}$ opinião de alguns professores, o construtivismo foi um modismo mal aplicado e mal trabalhado nas escolas, e que, com ele, o professor assumiu um novo papel. Parece que alguns desses professores são favoráveis ao construtivismo, mesmo sem saberem ao certo o que este representa para o contexto escolar.

(...) o Construtivismo falam assim: "(...) um método que não deu certo". Não, não é que ele não deu certo, mas quais foram as pessoas que foram trabalhar com esse método? Essas pessoas foram preparadas para realizar esse trabalho? Essas pessoas tiveram condições para realizar esse trabalho? (...) mas ele não foi aplicado, quem pegou ele foi trabalhado de uma forma muito superficial. (Prof. 06 - Escola A)

(...) mas era bonito falar que era Construtivista, estava na moda (...) virou um modismo mesmo (...). (Prof. 12 - Escola A)

(...) o aluno constrói o seu conhecimento, ou seja, o professor não é aquele só que transmite o conhecimento ao aluno (...). O papel dele é deixar o aluno ir descobrindo por si, levar o aluno a determinados caminhos que ele mesmo vai descobrir por si, ele vai construindo (...). (Prof. 03 Escola B)

(...) eu acho que o construtivismo é isso, trabalhar com o educando dentro da realidade dele. Eu acho isso. O Construtivismo constrói o aluno dentro do seu ambiente para o mundo exterior, eu acho isso muito válido, muito. (Prof. 08 - Escola B)

Uma minoria de professores parece ter uma visão mais crítica em relação ao construtivismo, ainda que não tenham conhecimento preciso sobre o assunto. Esses professores parecem não concordar com a implantação do construtivismo nas escolas.

(...) Construtivismo falava para a criança construir o seu conhecimento né, eu não acho que é deixar a criança construir (...) o que Piaget passou né, Vygotsky também trabalha o Construtivismo, a teoria deles, ela foi talvez, não sei se mal traduzida (...). Construtivismo não é isso. Não é soltar e deixar a criança fazer do jeito que ela quer (...). É por isso que eu te falo que eu não gosto muito do 
Construtivismo, não gosto como ele foi aplicado, se ele foi aplicado. (...) eu acho que a teoria de Vygotsky e Piaget foi mal interpretada (...). (Prof. 01 - Escola A)

(...) eu acho que tudo isso que eles colocam de teoria para gente é utopia, até esse Construtivismo. O Construtivismo que passaram nas escolas é maçante, é chato, é uma leitura chata, é ficar lendo Emília Ferreiro (...). Eu não sei o que é isso. Eles não explicam direito. Falam, falam e não falam nada. (Prof. 02 - Escola B)

Sobre "O Construtivismo e as Diferentes Redes de Ensino", alguns professores acreditam que não houve, nas escolas particulares ou públicas, um trabalho baseado na proposta construtivista.

Então eu cheguei a ver escolas que eu dei aula particular para um monte de crianças (...). Falava que era Construtivista, a escola claro! (...) mas eu não vi isso (...) quando ele começou a chegar na Escola Pública, eu acho que ele já chegou totalmente truncado, eu não acho que houve um trabalho construtivista nas Escolas Públicas (...). (Prof. 01 - Escola A)

Uns falam que em alguma escola particular está sendo feito e que em algum lugar está sendo aplicado o método construtivista, você vai lá e não é nada daquilo é, não é verdade? Você vai lá e é tudo a mesma coisa que a gente faz aqui (...). Na verdade ninguém sabe o que é construtivismo. Eu acho que nem as pessoas que aplicaram. (Prof. 01 Escola B)

Com relação aos "Estudos e Cursos sobre o Construtivismo", a maioria dos professores relatou não ter participado de estudos ou cursos a esse respeito. Os poucos que participaram relataram que os cursos foram superficiais e que os professores não levavam a sério tal trabalho. Comentaram também que, por mais que a experiência tenha sido válida, não houve continuidade dos cursos.

O Construtivismo você ia fazer um curso ali, um curso aqui, outro curso lá, eles eram vistos bem por cima, mas também ninguém sentava para estudar a fundo para ver o que é para aplicar de maneira certa, entendeu? (Prof. 01 - Escola A)

(...) eu tive um curso de três dias, eu achei ótimo o curso, mas a gente sabe que na hora de pôr em prática não dá (...). (...) a gente sempre aprende, mas depois disso já faz uns ... sete anos e mais, não tive mais nada que desse mais base para eu poder trabalhar mais (...). (Prof. 03 - Escola A)

(...) na Escola Padrão né, foi discutido (...) a coordenadora na época, trouxe muito material, lemos tudo, é aquela história na teoria uma coisa, na prática é outra. Ela trouxe recortes de jornal, de revistas, livros sobre Piaget, sobre que mais? mas fica só nisso (...). (Prof.01 - Escola B)

(...) é tudo de um dia para o outro, não tem curso, não tem nada, então você ouve: 'olha, o Construtivismo é assim'. (Prof. 15 - Escola B)

Quanto ao "Construtivismo e o Ensino e Aprendizagem", alguns professores gostariam de trabalhar com o Construtivismo, mas não se sentem preparados, precisariam de orientações, conhecimento sobre o assunto e de melhores condições em sala de aula. Para eles, dar uma aula diferente não significa ser construtivista.

Eu tenho dificuldades para trabalhar com o Construtivismo. (...) eu não estudei com este método. Então desconheço como trabalhar mesmo. (...) você procura dar, uma maneira diferente de dar, mas esta maneira diferente para mim não é o Construtivismo, você entendeu? A gente precisa ter mais condições dentro de sala, como fazer um trabalho adequado com 45 alunos? (...). (...) mas eu acho que o fator mais importante mesmo é a gente não ser preparada para isso. (Prof. 10 - Escola A)

O pessoal começou a usar de uma maneira sem retaguarda. (...) eu acho que ai é que a escola se perdeu, sabe, tá certo que tinha que ser mudado alguma coisa. Esta maneira de construir seria o ideal, mas eu acho que a grande maioria dos professores não estavam preparados, eu acho ainda que não estão preparados, eu acredito que ainda hoje tem muita gente querendo fazer alguma coisa, mas totalmente insegura e fica perdida (...). (Prof. 19 - Escola B)

Alguns professores afirmaram que o construtivismo é mais uma das imposições governamentais e que o docente, mais uma vez, não é consultado, é mal orientado e, consequentemente, não faz o trabalho acontecer.

(...) eu acho que ele foi mal interpretado e não aplicado como deveria (...) pegaram uma teoria e jogaram dentro da escola pública ou jogaram dentro da escola particular. (...) eu não gosto da maneira que ele foi aplicado, sem embasamento teórico, sem estudar a teoria a fundo (...). (Prof. 01 - Escola B)

Isso também é mais uma das coisas impostas pelo Governo, eles não falam o que vocês acham disso para aplicar e explicar o que é direitinho para gente e a gente ter a liberdade de falar sim ou não. Nesta escola não funciona, pode ser que na outra funcione. (Prof. 02 - Escola B)

Com relação à "Implantação do Construtivismo nas Escolas", a maioria dos professores acredita que os professores não foram preparados para esta mudança, que esta ocorreu muito repentinamente, gerando confusão e incerteza na maneira de conduzirem o trabalho pedagógico com os alunos.

(...) ele não sabe, ele não foi formado para trabalhar no Construtivismo (...) as escolas não prepararam os professores, simplesmente jogaram uma teoria que foi confundida com método. (Prof. 14 - Escola A)

(...) porque foi de repente: 'é construtivismo? então agora nós não precisamos mais corrigir cadernos, é só deixar a criança à vontade'. Então, muitos professores largaram as crianças mesmo (...) foi uma loucura (...) logo no começo do construtivismo, a criança chegava na $3^{a}$ e na $4^{a}$ série e você não entendia o que ele escrevia (...) e isso só ocorreu porque foi deixando. Foi logo quando comecei a lecionar, no O. J., em 91 (...) mas foi de repente, (...) de um ano para outro, sem preparo, sem cursos, sem nada. Então eles falavam: 'de hoje em diante não é mais o método tradicional, é o Construtivismo'. (Prof. 15 - Escola B) 


\section{Discussão}

O que parece ter ficado evidente nos relatos dos professores é que eles não são contra o construtivismo no campo educacional, mas sim contra a maneira como este foi implantado. Constata-se que os professores têm poucas informações sobre o assunto para chegarem à conclusão de que o construtivismo não é adequado para ser utilizado na prática.

A pesquisa de Torres (2004) aponta que o que os professores não aceitam são as informações inconsistentes que lhes foram passadas sobre o construtivismo. O trabalho de Silva (2005) demonstra que os professores e formadores não têm uma visão correta do construtivismo. Os conceitos são, em geral, distorcidos e baseados em slogans.

Para a maioria dos professores que participaram desta pesquisa, o construtivismo é um método de ensino. Para outros, este não passou de um modismo nas escolas. Considera-se que a imprecisão na definição do que seja o construtivismo dificultou a compreensão deste assunto.

Acredita-se que, se os professores tivessem recebido informações claras sobre o construtivismo, provavelmente teriam se beneficiado das contribuições dessa teoria para o contexto educacional ou, ainda, poderiam ter assumido uma posição, favorável ou não, sobre a questão.

Outro aspecto a destacar é que os professores se consideram incapazes de trabalhar com esta proposta de ensino por falta de preparo, de estudo, de cursos, de esclarecimentos e de orientações contínuas nas escolas. Os trabalhos de Brewer e Daane (2002), Tatto (1998; 1999), Welsch-Kinnucan e Jenlink (1998) confirmam que os professores, ao serem formados em programas de educação baseados no construtivismo, possuem um entendimento melhor do significado desta perspectiva, o que Ihes possibilita decidir se devem ou não inseri-la em suas práticas educacionais.

As pesquisas de Massabni (2005) e Ribeiro (1997) revelaram que os professores têm noção dos princípios construtivistas, valorizam e concordam com esses princípios e, ainda, consideram importante a sua aplicação no contexto escolar; porém têm dificuldades de inserir a teoria na prática.

Queiroz e Barbosa-Lima (2007) defendem que o construtivismo é de grande relevância para a educação e que este se tornou orientador para muitas pesquisas no campo da área de Ciências. Contudo, esses autores alertam que a maneira como o construtivismo está sendo aplicado não está correta.

Para alguns professores, o construtivismo não passa de uma imposição governamental. Além disso, parece que os que trabalharam com o construtivismo se sentiram pressionados a serem construtivistas mesmo sem saberem direito o que seria essa proposta de ensino.

As concepções que a maioria dos docentes entrevistados possui sobre o construtivismo apresentam-se de forma bastante genérica e, de certa forma, parecem ser vagas. De maneira geral, os professores acreditam que, com o construtivismo, o aluno constrói seu próprio conhecimento e o professor é simplesmente um orientador. Parece que os professores receberam informações distorcidas sobre o construtivismo. Nesse sentido, Carvalho (2001) esclarece que o construtivismo que chegou às escolas parece ter confundido ou desorientado mais do que esclarecido o trabalho do professor.

Os resultados deste trabalho também concordam com as conclusões da pesquisa de Welsch-Kinnucan e Jenlink (1998), na qual detectou-se que os professores consideram que, ao trabalhar com a perspectiva construtivista, os alunos são construtores de seu próprio conhecimento. O estudo de Brewer e Daane (2002) também demonstra que os professores acreditam que os alunos constroem seu próprio conhecimento a partir do conhecimento que já possuem. De acordo com o trabalho de Tatto (1998), os professores pesquisados apontaram que a principal função do professor é a de encorajar os estudantes a construírem seu conhecimento e a questionarem o mundo.

Os depoimentos denunciam que, ao mesmo tempo em que foi "jogado" nas escolas, o construtivismo foi retirado abruptamente das mesmas. Quando alterações significativas são realizadas nas escolas, o professor se sente perdido, insatisfeito, excluído e magoado frente à desqualificação e depreciação do seu trabalho e da sua pessoa. Nesse sentido, na pesquisa de Tatto (1999), alguns professores similarmente relataram que não será nada fácil pôr em prática a teoria construtivista se não tiverem apoio e orientação.

Para Macedo (1988), é importante retomar o caráter fundamental da formação de docentes para que estes compreendam a epistemologia que está por trás de sua prática, ou seja, a partir da reflexão de sua ação, diferenciar as tendências empiristas, apriorísticas e, se possível, construtivistas que permeiam seu trabalho enquanto professor. Somente por meio desse procedimento é que o professor terá oportunidade de assumir o construtivismo como melhor opção pedagógica; caso contrário, a adoção dos pressupostos piagetianos continuará a criar justaposições e a impressão de que houve mudança apenas superficial na educação brasileira.

\section{Conclusões}

A partir dos resultados obtidos, parece possível chegar às seguintes conclusões:

1) Os professores revelaram ter uma concepção de construtivismo imprecisa, insuficiente e, às vezes, equivocada. Parece que os professores tiveram contato com os discursos menos sistematizados e formalizados do construtivismo por meio de materiais difundidos por cursos, livros, revistas e até mesmo por meio de diálogos informais nas escolas, durante a troca de ideias e experiências com outros professores.

2) Parece ter ficado evidente nos relatos dos professores que eles não são contra o construtivismo no ensino, mas sim contra a maneira como este foi introduzido. Os professores queixam-se da falta de suporte teórico, de respaldo da equipe técnico/pedagógica e do desrespeito das políticas educacionais. Acredita-se que os professores 
não tiveram acesso aos pressupostos construtivistas, cujo principal representante foi Piaget.

3) Os relatos dos professores indicam que as reformas estão sendo feitas de forma impositiva e que, além de terem que assimilá-las rapidamente para utilizá-las, os professores não são incluídos nas elaborações das propostas e são muito mal informados.

4) Partindo do pressuposto de que o construtivismo foi transmitido de maneira inadequada aos professores, como esperar que os professores realizem reflexões coerentes e consistentes sobre os pressupostos construtivistas que poderiam subsidiar a sua prática?

\section{Referências}

Associação Nacional de Pós-Graduação e Pesquisa em Educação - ANPEd. (1996). Parâmetros Curriculares Nacionais. Revista Brasileira de Educação, 2, 85-92.

Azanha, J. M. P. (2001). Parâmetros Curriculares Nacionais e a Autonomia da Escola International Studies on Law and Education, 3, 23-32.

Bardin, L. (1979). Análise de conteúdo (L. A. Reto \& A. Pinheiro, Trad.). Lisboa: Edições 70

Brewer, J., \& Daane, C. J. (2002). Translating constructivist theory into practice in primary-grade mathematics. Education, 123(2), 399-416. Recuperado: 04 ago 2003. Disponível: http://www. sciencedirect.com/science/journal/0742051X.

Carvalho, J. S. F. (2001). Construtivismo - uma pedagogia esquecida da escola. Porto Alegre: Artmed.

Duarte, N. (2001). Vigotski e o "aprender a aprender": crítica às apropriações neoliberais e pós-moderna da teoria vigotskiana. Campinas, SP: Autores Associados.

Hernández, A. (1998). As visões do construtivismo: da formação do professorado às exigências da tarefa docente (C. Schilling, Trad.). Em M. J. Rodrigo \& J. Arnay (Orgs.), Domínios do conhecimento, prática educativa e formação de professores - a construção do conhecimento escolar (Vol. 2, pp. 123-138). São Paulo: Ática.

Macedo, L. (1988). Construtuvismo e aprendizagem da escrita. Boletim da Asociação Brasileira de Psicopedagogia, 15, 09-17.

Macedo, L. (1993). O construtivismo e sua função educacional Educação \& Realidade, 18(1), 25-31.

Macedo, L. (1994). Ensaios construtivistas (4a ed.). São Paulo: Casa do Psicólogo.

\section{Sobre os autores}

Patrícia Rossi Carraro (patrosca@usp.br)

Centro Universitário de Rio Preto e Faculdades Integradas Padre Albino - Catanduva/S.P

Antônio dos Santos Andrade (antandras@ffclrp.usp.br)

Faculdade de Filosofia Ciências e Letras de Ribeirão Preto da Universidade de São Paulo

\section{Correpsondência}

Patrícia Rossi Carraro

Endereço: Rua Tomás Nogueira Gaia, 1645, apt 22.

Bairro: Jardim Irajá Cidade: Ribeirão Preto/SP- Brasil CEP: 14020-290

\section{Agradecimentos}

Pesquisa apoiada pela FAPESP
Massabni, V. G. (2005). O construtivismo do professor: de Piaget às idéias e práticas de professores de Ciências. Tese de Doutorado, Universidade Estadual Paulista"Júlio de Mesquita", Faculdade de Ciências e Letras, Araraquara, São Paulo.

Minayo, M. C. S. (1998). O desafio do conhecimento: pesquisa qualitativa em saúde. São Paulo: HUCITEC-ABRASCO.

Moreira, A. F. B. (1996). Os Parâmetros Curriculares Nacionais em questão. Educação \& Realidade, 21(1), 9-22.

Piaget, J. (1976). A equilibração das estrututas cognitivas: problema central do desenvolvimento (M. M. S. Penna, Trad.). Rio de Janeiro: Zahar.

Piaget, J. (2000). Biologia e conhecimento: ensaio sobre as relações entre as relações orgânicas e os processos cognoscitivos (3a ed.). Petrópolis, RJ: Vozes.

Queiroz, G. R. P. C., \& Barbosa-Lima, M. C. A. (2007). Conhecimento científico, seu ensino e aprendizagem: atualidade do construtivismo. Ciência e Educação, 13(3), 273-291.

Ribeiro, M. C. F. (1997). Dois estudos sobre o construtivismo na teoria e na prática de professores. Dissertação de Mestrado, Universidade de São Paulo, São Paulo.

Silva, R. C. (2005). Saberes construtivistas de professores do ensino fundamental: alguns equívocos e seus caminhos. Tese de Doutorado, Universidade Estadual Paulista "Júlio de Mesquita", Faculdade de Ciências e Letras, Araraquara, São Paulo.

Souza, L. B. de S., \& Figueiredo, M. A. de C. (1993). A análise de conteúdo e crenças sobre o trabalho socializado para um estudo de atitude. Medicina, 26(2), 281-293.

Tatto, M. T. (1998). The influence of teacher education on teachers' beliefs about purposes of education, roles, and practice. Journal of Teacher Education, 49(1), 54-66. Recuperado: 23 set 2001. Disponível: http://www.sciencedirect.com/science/journal/0742051X

Tatto, M.T. (1999). Improving teacher education in rural Mexico: The challenges and tensions of construtivist reform. Teaching and TeacherEducation, 15, 15-35. Recuperado: 25 set2001. Disponível: http://www.sciencedirect.com/science/journal/0742051X

Torres, L.C. (2004). Do discurso pedagógico ao discurso dos professores: resistência ao construtivismo e profissionalização docente. Dissertação de Mestrado, Universidade Estadual Paulista“Júlio de Mesquita”, Faculdade de Ciências e Letras, Araraquara, São Paulo.

Welsch-Kinnucan, K., \& Jenlink, P. M. (1998). Challenging assumptions about teaching and learning: Three case studies in constructivist pedagogy. Teaching and Teacher Education, 14(4), 413-427. Recuperado: 25 jan 2009. Disponível: http://www. sciencedirect.com/science/journal/0742051X

Recebido em: 02/10/2008

Reformulado em: 03/07/2009

Aprovado em: 13/07/2009 